COMmENTARY ON COVID-19 AND THE FoOd SyStem

\title{
Community-led food resilience: Integrating grassroots food access into municipal emergency planning
}

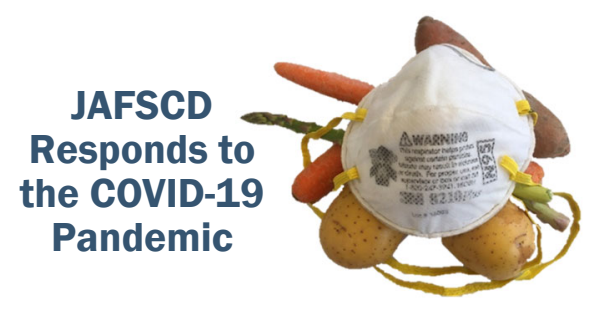

\author{
Sasha Avrutina a* \\ New York City \\ Hanah Murphy ${ }^{b}$ \\ Orlando, Florida \\ Eesha Patne ${ }^{c}$ \\ Baltimore, Maryland
}

Submitted September 20, 2020 / Published online October 30, 2020

Citation: Avrutina, S., Murphy, H., \& Patne, E. (2020). Community-led food resilience: Integrating grassroots food access into municipal emergency planning. Journal of Agriculture, Food Systems, and Community Development, 10(1), 215-217. https://doi.org/10.5304/jafscd.2020.101.011

Copyright (C) 2020 by the Authors. Published by the Lyson Center for Civic Agriculture and Food Systems. Open access under CC-BY license.

$\mathrm{T}$ he initial impact of the COVID-19 pandemic was a severely disrupted conventional food system, exacerbating issues of food access for populations previously experiencing food insecurity. Simultaneously, the number of individuals requiring food assistance continued to rise. In Baltimore City, municipal emergency responders who were activated as part of the city's food resilience plan worked overtime to coordinate adequate food access to communities in need. The challenges they faced were compounded by public health guidelines and policy restrictions, leaving common emergency food strategies such as community feeding untenable. However, the reaction to COVID-19 set the stage for new food response efforts outside the established network players. The need for a shift in food access strategies was answered by emergent, community-led partnerships engaging in responsive food recovery and distribution.

Typically, emergency food assistance relies on autonomous organizations, such as food banks and food pantries, and is not explicitly integrated into emergency management operations. Baltimore, however, has emerged as a national leader through the city's efforts to address community-driven

a* Corresponding author: Sasha Avrutina, Social Designer, New York City, New York; savrutina@mica.edu

b Hanah Murphy, Food System Designer, Orlando, Florida; hmurphy01@mica.edu

c Eesha Patne, Social Design Associate, Baltimore, Maryland; epatne@mica.edu

Acknowledgments

We'd like to thank the Baltimore Office of Sustainability and Mera Kitchen Collective for their contributions. 
emergency and long-term food security. Established in the aftermath of the Baltimore Uprisingsprotests following the death of Freddie Gray while in custody of the Baltimore police in 2015-the role of the Baltimore Office of Sustainability was essential in the city's coordination of food access actors present in their network.

Abby Cocke, an environmental planner for the Baltimore Office of Sustainability notes,

Community organizations were on our radar from the beginning because of our work with the Resilience Hubs, a network of major non-profits, faith institutions, and other community-centered organizations that serve their neighbors. We had been equipping these hubs with emergency supplies in case of climate disasters, and when COVID-19 hit, they were on our radar in terms of food because most already ran food pantries or soup kitchens, or else started them up quickly.

Despite the city's progressive emergency plan, the pandemic exposed the difference between those engaged in food access at the institutional and the hyperlocal grassroots level. Those referred to as "grassroots" are entities not previously named in the city of Baltimore's municipal emergency operations. From breweries producing hand sanitizer to restaurants donating meals, local food service businesses appropriately pivoted to fill specific needs within their community.

Among the many grassroots organizations working to address COVID-19-related food insecurity in Baltimore is Mera Kitchen Collective. Prior to COVID-19, Mera Kitchen Collective primarily hosted pop-up events and provided catering services. By utilizing their culinary background and talents, they support refugee and immigrant women through business development and food-based storytelling. Thanks to their pre-established commitment to creating positive change, they were able to form the partnerships needed to fully focus on providing food assistance to the Baltimore community during the pandemic. Through identifying key aspects of Mera Kitchen Collective's post-pandemic actions, the benefits that grassroots organizations bring to emergency responses become apparent.

\section{Shifting Priorities}

While the majority of commercial food service businesses were required to limit their person-to-person contact or shut down, Mera Kitchen Collective focused their energy to form a sustainable business model providing meals to those experiencing food insecurity. According to Aisha Alfadhalah, co-founder of Mera Kitchen Collective, their organization was hyper-aware of the importance of food assistance and mindful of how their business fit into the larger food network. This allowed them to showcase an agile shift in priorities to be able to respond to the crisis in real time. She says,

In March several of our catering events were canceled. We knew many will be hungry and our workers depend on the income they make, so we created a GoFundMe to support our meal program. ... We hope that by sharing delicious and healthy food, at an accessible price point, we can illustrate the economic, environmental and personal impact that we, as chefs and entrepreneurs, can have on the food system and individual livelihoods.

\section{Building Trust}

Typical emergency food procurement and distribution, while having greater access to institutional resources, often relies on generalized data and maps to make decisions about where to send food assistance. In many cases, the lack of direct and interpersonal relationships with community members leads to the people requiring services being overlooked for emergency assistance. Without a nuanced understanding of these needs, a sense of distrust between city institutions and communities is perpetu- 
ated, leaving people unsure of accepting assistance. Through intentional relationship-building with the community, Mera Kitchen Collective is a prime example of an organization widely viewed as reliable, rendering their efforts to provide assistance successful. Regarding these efforts, Alfadhalah shares, "Our business has always been about centering our workers and creating community. Many individuals in Baltimore believed in our business and supported us when we started. The response to community meals was reciprocal to the generosity that Baltimore gave us."

As noted in the Baltimore Food System Resilience Advisory Report, "Interviews with community members suggest strong social capital in some, but not all, Baltimore neighborhoods. A lack of trust in formalized city institutions could hinder community-level uptake of City-led resilience and preparedness strategies" (Biehl, Buzogany, Huang, Chodur, \& Neff, 2017, p. 3). Grassroots organizations like Mera Kitchen Collective demonstrate that through building rapport, organizations are able to be seen as a trustworthy resource and provide food assistance to more people because of it.

\section{Collaborating}

As food distribution was disrupted and service shut down, Alfadhalah mentions that partnerships were immediately formed with organizations "to increase [our] capacity in providing delicious and nutritious meals." Mera Kitchen Collective initially partnered with the restaurant Alma Cocina Latina to develop the Community Meals initiative. This partnership ensured income for workers of both organizations as well as free meals to those in need. Local farmers were also crucial partners in this effort, providing fresh produce while over 35 other groups and organizers distributed the food in their communities. In just the first three months of the initiative, their partnership provided over 54,000 free meals. This initiative would not have been as successful without the efforts of all organizations involved, emphasizing the importance of collaboration.

\section{Conclusion}

The characteristics of Mera Kitchen Collective's efforts have highlighted the fact that community-led emergency food initiatives are valuable resources and should be better integrated into emergency planning. Alfadhalah suggests, "City responses can work with local restaurants and small businesses in finding solutions and creating change in our society where quality food and dignifying labor is the center of the response." From Mera Kitchen Collective's perspective, "As food professionals, we dream to see a closer 'co-existence' within the urban communities through food . . . creating a dialogue and building bridges through food."

Partnering with grassroots organizations creates the link between institutions and communities, vital to addressing inequities and building long-term resilience. Food insecurity doesn't begin or end with the COVID-19 pandemic. There is still a long way to go to ensure equitable food security in the face of other food systems hazards, even in times of relative normalcy. As the likelihood of future pandemics and other kinds of disturbances increases, it is imperative to understand the characteristics that allowed these organizations to quickly address the gaps in equitable food access and long-term food system resilience. The work of Mera Kitchen Collective demonstrates how cities can rethink ways of approaching emergency food assistance centered on collaboration and trust.

\section{Reference}

Biehl, E., Buzogany, S., Huang, A., Chodur, G., \& Neff, J. (2017). Baltimore Food System Resilience Advisory Report.

Baltimore, Maryland: Johns Hopkins Center for a Livable Future. Retrieved from

https://clf.jhsph.edu/sites/default/files/2019-01/baltimore-food-system-resilience-advisory-report.pdf 